\title{
Bevacizumab as an Adjuvant in Management of Glaucoma
}

\author{
Sushmita Kaushik, Parul Ichhpujani, Surinder Singh Pandav \\ Advanced Eye Center, Postgraduate Institute of Medical Education and Research, Chandigarh, India
}

\begin{abstract}
Recent research has shown a large number of growth factors to be responsible for neovascularization. Vascular endothelial growth factor has been identified to play a key role in ocular angiogenesis. Bevacizumab, a humanized monoclonal antibody that binds to all isoforms of vascular endothelial growth factor has shown promising results in regression of neovascularization. The use of Bevacizumab has been reported extensively in various retinal pathologies including proliferative diabetic retinopathy, cystoid macular edema, neovascular age-related macular degeneration, and neovascular glaucoma, but the clinical use in glaucoma is not yet clear. The glaucoma filtering surgery entails fashioning an external filter for aqueous drainage and a prerequisite to its optimum functioning is a patent filtering bleb. Since fibroblast function and growth of new vessel is a component of healing of the bleb there have been attempts to retard this healing by the use of Bevacizumab. This article reviews the current clinical studies documenting the use of Bevacizumab in glaucoma.
\end{abstract}

\section{INTRODUCTION}

Neovascularization derived from different tissues share some common mechanisms. In recent years, the most popular one supported by mounting evidences is the role of growth factors in the development of neovascularization. The role of growth factors in ocular vascular development was first postulated in 1954 by Michaelson, ${ }^{1}$ who hypothesized that the development of retinal vasculature is mediated by a diffusible substance produced in the retina. This hypothesis was supported by the identification of a large number of growth factors. In the past two decades extensive research has been done to define their role in promoting angiogenesis in the eye. The most important angiogenic factors in ocular neovascularization include VEGF (vascular endothelial growth factor), ${ }^{2-5} \mathrm{bFGF}^{6}$ (Fibroblast growth factor), IGF-1 ${ }^{7}$ (Insulin like growth factor), and EGF (epithelium growth factor). ${ }^{8}$ Anterior segment neovascularization results from several ocular and systemic diseases that predispose patients to retinal hypoxia and ischemia with subsequent release of angiogenesis factors such as VEGF. Several Anti-VEGF agents have been tried recently in an effort to retard the effects of VEGF including Bevacizumab, Ranibizumab and Pegaptanib sodium. Bevacizumab is being used commonly for retinal diseases but still there is a limited experience for glaucoma. This review would look at the current status and usage of Bevacizumab for management of glaucoma.

\section{VASCULAR ENDOTHELIAL GROWTH FACTOR (VEGF)}

Vascular endothelial growth factor is a 46-kDa homodimeric glycoprotein first identified in highly vascularized tumors in 1983. ${ }^{9}$ Four VEGF isoforms (VEGF121, VEGF165, VEGF189, and VEGF206) have been identified, which are generated by alternative mRNA splicing from the same gene. ${ }^{10}$ VEGF165 is the most abundant molecular species in the majority of tissues. ${ }^{10}$ It is a potent angiogenic stimulator, promoting several steps of angiogenesis, including proliferation, migration, proteolytic activity and capillary tube formation of endothelial cells, thus playing a crucial role in both normal and pathological angiogenesis. ${ }^{11,12}$ VEGF is also known as vascular permeability factor (VPF), based on its ability to induce vascular hyperpermeability ${ }^{9,11,12}$ and endothelial cell proliferation and migration. VEGF exerts its action through two known VEGF receptors, VEGFR-1 (fms-like tyrosine kinase-1 or Flt-1) and VEGFR-2 (kinase insert domain-containing receptor or Flk-1/ KDR), which are expressed predominantly in endothelial cells, and to a lesser extent on monocytes and macrophages. ${ }^{13}$ The binding of VEGF to its receptors initiates a signal transduction cascade mediating vascular permeability.

\section{BEVACIZUMAB: AN ANTI-VEGF AGENT}

Bevacizumab (Avastin ${ }^{\circledR}$ Genentech, San Francisco, California, USA), a recombinant antibody against vascular endothelial growth factor is Food and Drug Administration-approved for the treatment of colorectal cancer. ${ }^{14}$ Bevacizumab is an antibody made partially of a murine protein that comes from Chinese hamster ovary cells. Several case series have been published regarding the off-label use of intravitreal bevacizumab (IVB) for the treatment of proliferative diabetic retinopathy, ${ }^{15}$ cystoid macular edema, ${ }^{16}$ neovascular age-related macular degeneration, ${ }^{17,18}$ and few cases of neovascular glaucoma (NVG). ${ }^{19,20}$ It is a full sized antibody (half life of upto 20 days), ${ }^{21}$ which may account for its potential for inflammation and immune reactions. 


\section{ROLE OF BEVACIZUMAB IN NEOVASCULAR GLAUCOMA}

Neovascular glaucoma is a serious complication caused by ischemic retinopathies such as diabetic retinopathy ${ }^{22}$ and central retinal vein occlusion. Standard treatment modalities comprise retinal photocoagulation, artificial glaucoma drainage procedures using valves or tubes and cyclodestruction in eyes with no visual potential. ${ }^{23}$ Several case studies have attempted to ascertain the value of intraocular anti-VEGF therapy with Bevacizumab as an adjunctive treatment for iris neovascularization associated with glaucoma. ${ }^{15,20,29}$

Oshima et $\mathrm{al}^{15}$ reported a case series of 7 eyes with neovascularization of iris (NVI) secondary to proliferative diabetic retinopathy. The NVI regressed in all patients at one week and repeated injections stabilized the recurrence (2 eyes) that was seen two months after the initial injection. Intraocular pressure (IOP) was controlled in six eyes throughout the follow up period with no inflammation or complications.

Tripathi et al ${ }^{24}$ have shown that patients with NVG had a significantly increased level of VEGF in the aqueous humor. They have discussed the possible role of ciliary epithelium, in addition to retina, in the production of VEGF and the complementary function of basic fibroblast growth factor (bFGF) and other growth factors.

Grover et $\mathrm{a}^{30}$ have also shown increased aqueous VEGF concentrations in two patients with NVI, which significantly declined, with concurrent resolution of NVI, after off-label intracameral injections of bevacizumab. They used a highly sensitive multiplex analysis, which affords increased sensitivity in detecting VEGF (lowest detected concentration of $1.5 \mathrm{pg} / \mathrm{ml}$ ), highly reliable results as each bead assessed is a replicate, and requires a small sample size (typically 100 microl). In line with previous studies ${ }^{31}$ reporting resolution of NVI after cyclophotocoagulation, this study also implicates the ciliary body epithelium as a potential source of continued VEGF production and provides the rationale for intracameral anti-VEGF treatment.

Davidorf et $\mathrm{al}^{20}$ described a case of choroidal melanoma with diabetes treated with transpupillary thermotherapy and panretinal photocoagulation (PRP) which subsequently developed NVG. The patient was treated with intravitreal injection of $1.25 \mathrm{mg}$ Bevacizumab and the NVI regressed. Subsequently trabeculectomy was performed and intraoperatively the angle was found to be avascular. Intraocular pressures were controlled and no further laser or treatment was required for that patient.

Mason et $\mathrm{al}^{25}$ used intravitreal Bevacizumab in three patients who had undergone PRP and had developed NVG. All three showed regression of neovascularization of iris (NVI) and only one patient required tube surgery, others being managed with topical medication. They proposed IVB for patients with NVG, recurrent hemorrhages from NVI and for those who despite PRP develop NVI. Tube drainage procedures may be potentially avoided by giving an IVB injection, which may cause immediate regression of iris and angle neovascularization thus allowing for a better IOP control with topical hypotensives.

Iliev et $\mathrm{al}^{26}$ have described six consecutive patients with NVG and refractory, symptomatic elevation of IOP with NVI, who received IVB $(1.25 \mathrm{mg} / 0.05 \mathrm{ml})$. A marked regression of anterior segment neovascularization and relief of symptoms was noted within 48 hours. IOP decreased substantially in three eyes while other three eyes required adjuvant cyclophotocoagulation (eyes that had PAS at the time of NVG diagnosis). No side effects were observed.

Grisanti et $\mathrm{al}^{27}$ used intracameral injection of $1.0 \mathrm{mg}$ Bevacizumab in six eyes of three patients with secondary NVG due to proliferative diabetic retinopathy $(\mathrm{n}=2)$ or ischemic central retinal vein occlusion $(\mathrm{n}=1)$. As early as one day after injection decrease in leakage was detected by iris fluorescein angiography. No inflammation or relapse was seen within the follow-up of four weeks. So they proposed that intracameral injection of Bevacizumab may provide an additional strategy for the treatment of iris rubeosis in neovascular glaucoma. Similar report by Avery ${ }^{28}$ demonstrated regression of retinal and iris neovascularization due to proliferative diabetic retinopathy with IVB.

Vatavak and co workers ${ }^{29}$ reported a case of NVG due to central retinal artery occlusion treated with a single injection IVB (1.25 mg Bevacizumab/0.1 mL). Iris and angle neovascularization regressed within 48 hours of the injection along with significant reduction of intraocular pressure. PRP was applied 4 weeks after the injection so they proposed Bevacizumab to be a useful adjunct to PRP.

In a retrospective, consecutive case-control study, 11 patients receiving same-day combination therapy with IVB and PRP were compared with 12 patients who received PRP alone as treatment of NVG. The combination group had a significant reduction in IOP compared with the PRP-only group ( -11 vs 0 $\mathrm{mm} \mathrm{Hg} ; \mathrm{p}=0.03$ ) and there was a significantly higher rate and speed of neovascular regression in the combination group than in the PRP-only group ( $100 \%$ in 12 days vs $17 \%$ in 127 days). ${ }^{32}$

Fakhraie et al in a prospective, non comparative case series of NVG patients who had not responded to or could not receive PRP found that preoperative IVB combined with guarded filtration surgery with mitomycin $\mathrm{C}$ is a safe and effective method of controlling intraocular pressure in NVG. ${ }^{33}$

Studies have also shown that eyes with peripheral anterior synechia or angle closure at the time of presentation are less likely to achieve a lowering of their IOP with IVB, and more likely to need glaucoma surgery. Longstanding changes in the anatomy of the trabecular meshwork preclude improvement in IOP despite the induction of regression of neovascularization. ${ }^{34,35}$ Gheith et al reported the use of IVB for NVG in six 
eyes; those eyes with PAS at the time of presentation needed subsequent glaucoma surgery,while those eyes without PAS required only topical medication to control IOP. ${ }^{34}$

Simultaneous intravitreal and intracameral injection of bevacizumab has been shown to cause an immediate regression of neovascularization secondary to PDR or CRVO, which in turn can prevent dense PAS formation that can lead to persistent IOP increasing. ${ }^{36}$

Most previously mentioned reports included relatively small numbers of eyes and had limited follow-up. A study by Moraczewski ${ }^{37}$ described a comparatively larger series of 56 eyes with NVG treated with intravitreal bevacizumab. They found that the Kaplan-Meier cumulative proportion of eyes with open angles receiving a glaucoma drainage device after initial bevacizumab injection was not statistically significantly different from that of eyes with closed angles.

All eyes injected with bevacizumab for NVG must be monitored carefully long-term, regardless of initial angle status and initial IOP lowering as they may require surgical intervention for better control of IOP.

\section{ROLE OF BEVACIZUMAB IN OCULAR ISCHEMIC SYNDROME}

About two-thirds of patients with ocular ischemic syndrome (OIS) present with NVI, with one-third of those developing NVG. Given the high visual morbidity associated with NVG in OIS and the relatively poor response of NVI to PRP for ocular ischemic syndrome, one may consider intravitreal bevacizumab in eyes that have persistent anterior segment neovascularization after standard PRP has been performed. ${ }^{38}$

\section{ROLE OF BEVACIZUMAB IN FILTERING SURGERY}

Angiogenesis forms an integral part of wound healing which is an unwanted process in the postoperative period after antiglaucomatous filtering surgery.

Adjunctive IVB at the time of trabeculectomy and valve implant surgery for neovascular glaucoma has been reported. ${ }^{33}$ Early limited reports do not clarify the clinical benefit of IVB in filtering surgery. ${ }^{39,40}$

Jonas et a ${ }^{41}$ reported two patients who underwent standard anti glaucoma penetrating filtering surgery combined with an intravitreal application of Bevacizumab. In both the patients the intraocular pressure was between 10-14 mm Hg, up to 12 weeks postoperative. So they concluded that intravitreal Bevacizumab may potentially be an adjuvant to filtering surgery, particularly in neovascular glaucoma.

Gupta et al ${ }^{42}$ evaluated the effect of $1.25 \mathrm{mg}$ and $2.5 \mathrm{mg}$ intracameral bevacizumab on surgical outcomes of trabeculectomy for NVG, with primary outcome measures being the regression of NVI and reduction of intraocular pressure. They found that the efficacy of an intracameral dose of $2.5 \mathrm{mg}$ of bevacizumab prior to trabeculectomy for eyes with NVG is not significantly different from a $1.25 \mathrm{mg}$ dose.

\section{ROLE OF BEVACIZUMAB IN BLEB REVISION}

Bleb failure is a major factor limiting the long-term success of trabeculectomy surgery. The process of bleb failure involves vascularization with fibroblast migration and eventual scarring of the fistula tract. One case report describes the use of bevacizumab in bleb needling revision in a patient with a failing bleb.

Kahook et a ${ }^{43}$ reported a case with previously failed needle bleb revision with mitomycin $\mathrm{C}$ and after needling and injection of $1 \mathrm{mg}$ of Bevacizumab, the bleb became more diffuse with a decrease in surface neovascularization.

\section{CONCLUSION}

Inhibiting angiogenesis is a promising strategy for the treatment of anterior segment neovascularization and neovascular glaucoma, if the angle is not totally closed from the peripheral anterior synechiae or damaged from the fibrovascular membrane. Bevacizumab may also be promising in rescuing a failing filtering bleb. The neovascularization can recur if the ischemic process is not reversed. Several issues like duration of action of Bevacizumab and toxicity profile on corneal endothelium, lens and trabecular meshwork, need to be addressed. It is also important to know whether Bevacizumab blocks all the VEGF at once or does it continue blocking until the antibodies are saturated.

There is a need for controlled prospective trials to establish long-term safety, efficacy and dosing guidelines in retinal ischemia and neovascular glaucoma.

\section{REFERENCES}

1. Michaelson IC. Retinal Circulation in Man and Animals, Charles C. Thomas, Springfield IL 1954.

2. Loughman MS, Chatzistefanou K, Gonzalez EM, Flynn E, Adamis AP, et al. Experimental corneal neovascularisation using sucralfate and basic fibroblast growth factor. Aust. NZ J Ophthalmol 1996;24:289-95.

3. Amano S, Rohan R, Kuroki M, Tolentino M, Adamis AP. Requirement for vascular endothelial growth factor in woundand inflammation-related corneal neovascularization. Invest. Ophthalmol. Vis Sci 1998;39:18-22.

4. Lee DH, Cho HJ, Kim JT, Choi JS, Joo CK. Expression of vascular endothelial growth factor and inducible nitric oxide synthase in pterygia. Cornea 2001;20:738-42.

5. Jin J, Guan M, Sima J, Gao G, Zhang M, Liu Z, Fant J, Ma JX. Decreased pigment epithelium-derived factor and increased vascular endothelial growth factor levels in pterygia. Cornea, 2003;22:473-77.

6. Hanneken A, de Juan EJ, Lutty GA, Fox GM, Schiffer S, et al. Altered distribution of basic fibroblast growth factor in diabetic retinopathy. Arch Ophthalmol 1991;109:1005-11. 
7. Meyer-Schwickerath R, Pfeiffer A, BlumWF, Freyberger H, Klein M, Losche C, Rollmann R, Schatz H. Vitreous levels of the insulin-like growth factors I and II, and the insulin-like growth factor binding proteins 2 and 3, increase in neovascular eye disease. Studies in nondiabetic and diabetic subjects. J Clin Invest 1993;92:2620-25.

8. Patel B, Hiscott P, Charteris D, Mather J, McLeod D. Retinal and preretinal localisation of epidermal growth factor, transforming growth factor alpha, and their receptor in proliferative diabetic retinopathy. Br J Ophthalmol 1994;78:71418.

9. Senger DR, Ledbetter SR, Claffey KP, Papadopoulos-Sergiou A, Peruzzi CA, et al. Stimulation of endothelial cell migration by vascular permeability factor/vascular endothelial growth factor through cooperative mechanisms involving the alpha-beta 3 integrin, osteopontin, and thrombin. Am J Pathol 1996;149:293305.

10. Ferrara N, Houck KA, Jakeman LB, Winer J, Leung DW. The vascular endothelial growth factor family of polypeptides. J Cellular Biochem 1991;47:211-18.

11. Dvorak HF, Brown LF, Detmar M, Dvorak AM. Vascular permeability factor/vascular endothelial growth factor, microvascular hyperpermeability and angiogenesis. Am J Pathol 1995;146:1029-39.

12. Aiello LP, Wong JS. Role of vascular endothelial growth factor in diabetic vascular complications. Kidney Int Suppl 2000;77:S113-19.

13. de Vries C, Escobedo JA, Ueno H, Houck K, Ferrara N, Williams LT. The fms-like tyrosine kinase, a receptor for vascular endothelial growth factor. Science 1992;255:989-91.

14. Hurwitz H, Fehrenbacher L, Novotny W, et al. Bevacizumab plus irinotecan, fluorouracil, and leucovorin for metastatic colorectal cancer, N Engl J Med 2004;350:2335-42.

15. Oshima Y, Sakaguchi H, Gomi F, Tano Y. Regression of Iris neovascularization after Intravitreal injection of Bevacizumab in patients with Proliferative Diabetic retinopathy. Am J Ophthalmol 2006;142:155-58.

16. Rosenfeld PJ, Fung AE, Puliafito CA. Optical coherence tomography findings after an intravitreal injection of bevacizumab (Avastin) for macular edema from central retinal vein occlusion, Ophthalmic Surg Lasers Imaging 2005;36:336-39.

17. Rosenfeld PJ, Moshfeghi AA, Puliafito CA. Optical coherence tomography findings after an intravitreal injection of bevacizumab (Avastin) for neovascular age-related macular degeneration. Ophthalmic Surg Lasers Imaging 2005;36:331-35.

18. Avery RL, Pieramici DJ, Rabena MD, Castellarin AA, Nasir MA, Giust MJ. Intravitreal bevacizumab (Avastin) for neovascular age-related macular degeneration, Ophthalmology 2006;113:363-72.

19. Kahook MY, Schuman JS, Noecker RJ. Intravitreal bevacizumab in a patient with neovascular glaucoma, Ophthalmic Surg Laser imaging 2006;37:144-46.

20. Davidorf FH, Mouser JG, Derick RJ. Rapid improvement of rubeosis iridis from a single bevacizumab (Avastin) injection, Retina 2006;26:354-56.

21. Beer PM, Wong SJ, Hammad AM, Falk NS, O’Malley MR, Khan S. Vitreous levels of unbound bevacizumab and unbound vascular endothelial growth factor in two patients. Retina 2006;26(8):871-76.

22. Fernandez-Vigo J, Castro J, Macarro A. Diabetic iris neovascularization. Natural history and treatment. Acta Ophthalmol Scand 1997;75:89-93.

23. Sivak-Callcott JA, O’Day DM, Gass DM, Tsai JC. Evidencebased recommendations for the diagnosis and treatment of neovascular glaucoma. Ophthalmology 2001;108:1767-76.

24. Tripathi RC, Li J, Tripathi BJ, Chalam KV, Adamis AP. Increased level of vascular endothelial growth factor in aqueous humour of patients with neovascular glaucoma. Ophthalmology 1998;105:232-37.

25. Mason JO, Albert MA, Mays A, Vail R. Regression of neovascular iris vessels by intravitreal injection of Bevacizumab. Retina 2006;26(7):839-41.

26. Iliev DM, Domig U, Wolf-Schnurrbursch S, Wolf GS. Intravitreal Bevacizumab (Avastin ${ }^{\circledR}$ ) in the Treatment of Neovascular Glaucoma. Am J Ophthalmol 2006;142(6):1054-56.

27. Grisanti S, Biester S, Peters S, Tatar O, Ziemssen F, BartzSchmidt K. Intracameral Bevacizumab for Iris Rubeosis. Am J Ophthalmol 2006;142(1):158-60.

28. Avery RL. Regression of retinal and iris neovascularization after intravitreal Bevacizumab (Avastin) treatment. Retina 2006;26(3):352-54.

29. Vatavuk Z, Bencic G, Mandic Z. Intravitreal Bevacizumab for neovascular glaucoma following central retinal artery occlusion. Eur J Ophthalmol 2007;17:269-71.

30. Grover S, Gupta S, Sharma R, Brar VS, Chalam KV. Intracameral bevacizumab effectively reduces aqueous vascular endothelial growth factor concentrations in neovascular glaucoma. $\mathrm{Br} \mathrm{J}$ Ophthalmol 2009;93:273-74.

31. Herell PK, Tripathi RC,Whiteside BC, et al. The use of contact transscleral Nd:YAG cyclophotocoagulation in neovascular glaucoma (ARVO abstract). Invest Ophthalmol Vis Sci 1997;38:S171.

32. Ehlers JP, Spirn MJ, Lam A. Combination intravitreal bevacizumab/panretinal photocoagulation versus panretinal photocoagulation alone in the treatment of neovascular glaucoma. Retina 2008;28(5):696-702.

33. Fakhraie G, Katz LJ, Prasad A, et al. Surgical Outcomes of Intravitreal Bevacizumab and Guarded Filtration Surgery in Neovascular Glaucoma. J Glaucoma, 2009 Jul 9. [Epub ahead of print].

34. Gheith ME, Siam GA, de Barros DS, et al. Role of intravitreal bevacizumab in neovascular glaucoma. J Ocul Pharmacol Ther 2007;23(5):487-91.

35. Wakabayashi T, Oshima Y, Sakaguchi H, et al. Intravitreal bevacizumab to treat iris neovascularization and neovascular glaucoma secondary to ischemic retinal diseases in 41 consecutive cases. Ophthalmology 2008;115(9):1571-80.

36. Yuzbasioglu E, Artunay O, Rasier R, Sengul A, Bahcecioglu H. Simultaneous intravitreal and intracameral injection of bevacizumab (Avastin) in neovascular glaucoma. J Ocul Pharmacol Ther 2009;25(3):259-64.

37. Moraczewski AL, Lee RK, Palmberg PF, Rosenfeld PJ and Feuer WJ. Outcomes of treatmet of neovascular glaucoma with intravitreal Bevacizumab Br J Ophthalmol 2009;93;589-93. 
38. Amselem L, Montero J, Diaz-Llopis M, et al. Intravitreal bevacizumab (Avastin) injection in ocular ischemic syndrome. Am J Ophthalmol 2007;144(1):122-24.

39. Kitnarong N, Chindasub P, Metheetrairut A. Surgical outcome of intravitreal bevacizumab and filtration surgery in neovascular glaucoma. Adv Ther 2008;25(5):438-43.

40. Sothornwit N. Intravitreal bevacizumab for ahmed glaucoma valve implantation in neovascular glaucoma: A case report. J Med Assoc Thai 2008;91(Suppl 1):S162-65.

41. Jonas JB, Spandau UH, Schlichtenbrede F. Intravitreal Bevacizumab for filtering surgery. Ophthalmic Res 2007;39:12122.

42. Gupta V, Jha R, Rao A, Kong G, Sihota R. The effect of different doses of intracameral bevacizumab on surgical outcomes of trabeculectomy for neovascular glaucoma. Eur J Ophthalmol 2009;19(3):435-41.
43. Kahook MY, Schuman JS, Noecker RJ. Needle bleb revision of encapsulated filtering bleb with Bevacizumab. Ophthalmic Surg Lasers Imaging 2006; 37(2):148-50.

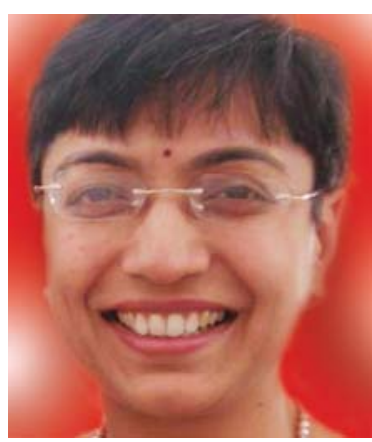

Sushmita Kaushik (sushmita_kaushik@yahoo.com)
If we don't believe in freedom of expression for people we despise, we don't believe in it at all. -Noam Chomsky 